\title{
VENTRICULOMEGALIA CEREBRALĂ FETALĂ „BORDERLINE“
}

\author{
Claudiu Mărginean ${ }^{1,2}$, Bela Szabo ${ }^{1,2}$, Nicoleta Suciu' ${ }^{1}$, Lorena Melițit,3, \\ Andrada Ioana Crişann ${ }^{1}$, Maria Oana Mărginean ${ }^{1}$, George Rolea ${ }^{4}$ \\ ${ }^{1}$ Universitatea de Medicină şi Farmacie, Tîrgu Mureş \\ ${ }^{2}$ Clinica de Obstetrică-Ginecologie 1, Tîrgu Mureş \\ ${ }^{3}$ Clinica de Pediatrie 1, Tîrgu Mureş \\ ${ }^{4}$ Departamentul de Obstetrică-Ginecologie, Spitalul Municipal, Sighişoara
}

\begin{abstract}
REZUMAT
Ventriculomegalia reprezintă dilatarea ventriculilor cerebrali peste $10 \mathrm{~mm}$, fiind clasificată în uşoară sau „borderline“ (10-12 mm), moderată $(13-15 \mathrm{~mm})$ şi severă (peste $15 \mathrm{~mm})$. Incidența variază foarte mult în funcție de tehnica utilizată şi de vârsta gestațională. Locul de elecție pentru măsurarea cea mai exactă a diametrului ventricular este la nivelul glomusului plexului coroid. RMN-ul este o altă metodă de evaluare a creierului fetal care permite, de asemenea, vizualizarea suprafeței cerebrale. Ventriculomegalia unilaterală este cauzată de obstrucția morfologică, fizică sau funcțională a orificiului Monro. Ventriculomegalia „borderline“ poate fi asociată cu anomalii cromozomiale, infecții congenitale, accidente vasculare cerebrale sau hemoragie, precum şi cu alte anomalii extracerebrale. Factori care influențează prognosticul copiilor diagnosticați cu ventriculomegalie uşoară sunt: sexul, vârsta gestațională, dimensiunea ventriculilor, afectarea uni- sau bilaterală, ventriculomegalie bilaterală simetrică sau asimetrică, progresia ventriculomegaliei - probabil cel mai important factor al prognosticului, regresia ventriculomegaliei. Părinții trebuie informați despre faptul că există limitări ultrasonografice în diferențierea unei ventriculomegalii „borderline“ izolate şi ventriculomegalie asociată unor altor anomalii oculte, care nu pot fi identificate inițial în vederea luării unei decizii adecvate. Ecografia fetală de control este de preferat a se efectuat după aproximativ 1-2 săptămâni de la diagnosticul inițial de „ventriculomegalie“.
\end{abstract}

Cuvinte cheie: ventriculomegalie, creier fetal, ultrasunete fetale, RMN cerebral

\section{DEFINIȚIE ŞI INCIDENȚĂ}

Ventriculomegalia este o patologie congenitală, care constă în dilatarea ventriculilor cerebrali peste $10 \mathrm{~mm}$. În funcție de gradul dilatării, aceasta se împarte în ventriculomegalie uşoară, atunci când dimensiunea ventriculilor este între $10-15 \mathrm{~mm}$ şi ventriculomegalie severă, când aceasta depăşeşte 15 mm (1-4). Referitor la definiţia ventriculomegaliei „,borderline“, există studii şi date controversate, astfel că anumiți autori au considerat acest termen ca fiind un sinonim pentru ventriculomegalie uşoară (5), pe când alții au concluzionat că aceasta ar trebui să se limiteze la o dimensiune ventriculară sub 12 $\mathrm{mm}(6,7)$. Ulterior a fost introdus termenul de ventriculomegalie moderată, care presupune o lățime a ventriculului între 13-15 mm (8). În ceea ce priveşte dimensiunea prag de la care trebuie considerată ventriculomegalie, Oggè et al consideră că aceasta ar trebui scăzută la 9,5 mm (9). În majoritatea cazurilor, ventriculomegalia este o patologie izolată, dacă nu se decelează prin ultrasonografie alte malformaţii asociate sau markeri de aneuploidie în momentul diagnosticului $(3,5)$. Prin definiție, acesta este un diagnostic temporar de excludere (10).

\section{Incidență}

Incidenţa ventriculomegaliei raportată în literatura de specialitate variază foarte mult, din cauza diferențelor de tehnică utilizată sau a vârstei gestaționale a feților incluşi în studiu. Astfel, cu cât vârsta gestațională e mai mare, cu atât şi prevalența ventriculomegaliei va fi mai mare. Două studii efectuate pe populații cu risc scăzut au raportat o incidență de 1:50, respectiv 1:1.600 $(11,12)$. Pe de altă parte, studii ulterioare au indicat incidențe de sub $1 \%$ pentru ventriculomegalia uşoară, astfel: $0,07 \%$ 
(13), $0,15 \%$ (14) sau chiar $0,88 \%$ (15). Oricum, în majoritatea studiilor, din cauza dificultăților tehnice, ventriculomegalia a fost diagnosticată doar prin măsurarea diametrului ventricului lateral distal de transductor (10). Ecografia craniană fetală include obligatoriu evaluarea ventriculului lateral (16).

\section{Măsurători ultrasonografice ale ventriculilor laterali cerebrali fetali}

Limitările tehnologice ale aparatelor de ultrasonografie existente în diverse centre medicale pot duce la un exces al diagnosticului fals-pozitiv. Astfel, ca în cazul multor examinări, medicul evaluează doar emisfera distală de transductor, ceea ce duce la pierderea de informații valoroase asupra emisferei proximale şi a asimetriei cerebrale. Setările ecografului utilizat sunt foarte importante, astfel că un contrast prea puternic poate duce la supraestimarea diagnosticului de ventriculomegalie. Frecvența pentru evaluările de bază ale creierului fetal sunt de 3,5-5 MHz, în scanarea abdominală, însă frecvențele de 5-10 MHz utilizate în cazul depistării unor anomalii, oferă o rezoluție mai bună. Locul de elecție pentru măsurarea cea mai exactă a diametrului transvers al atriului ventricular este la nivelul glomusului plexului coroid $(17,18)$. Există, de asemenea, o diferență a măsurătorilor în funcție de sex, astfel că ventriculii laterali au dimensiuni uşor mai mari, dar semnificativ statistice, în cazul sexului masculin comparativ cu cel feminin $(12,19)$. Dacă în cazul valorilor normale ale ventriculilor laterali în trimestrul 3 de sarcină există multe controverse, în cazul trimestrului 2 de sarcină s-a ajuns la un consens, şi anume o valoare medie de aproximativ $7 \mathrm{~mm}$, cu o deviație standard de $1 \mathrm{~mm}(11,12,19)$. Guibad et al au propus o standardizare a locului de elecție pentru măsurarea ventriculului lateral, şi anume în secțiunea cu cavum septum pellucidum şi triunghiul în formă de „V“ $\mathrm{V}$ " plin cu lichid al cisternei magna (20). Ulterior, ISUOG a emis recomandările minime necesare pentru evaluarea anatomiei fetale în trimestrul 2 de sarcină referitoare la aspectul ventriculilor (21). Astfel, abordarea multiplanară este cea recomandată în cazul suspiciunii unei anomalii a sistemului nervos central. Abordul transvaginal cu rezoluție înaltă oferă cele mai bune detalii atunci când fătul este în poziție cefalică. Măsurarea recomandată de ghidul ISUOG, în atriu, la glomus, este reprodusă în Fig. 5.

RMN-ul creierului fetal este o altă metodă de evaluare a sistemului nervos central fetal, care aduce informații suplimentare față de ultrasonografie în anumite cazuri. Avantajul acestei examinări este că permite, de asemenea, evaluarea suprafeței cere- brale fetale şi este de preferat a fi efectuată în trimestrul 3 de sarcină, între săptămânile 30-32 de gestație (22-29).

\section{INCERTITUDINI DE DIAGNOSTIC}

\section{Progresia dilatării ventriculare}

Studiile sugerează că riscul de progresie a dilatării ventriculare după diagnosticul inițial este de $11-15,7 \%$, cu asocierea ulterioară a depistării altor anomalii fetale, care nu au fost identificate inițial $(10,30)$.

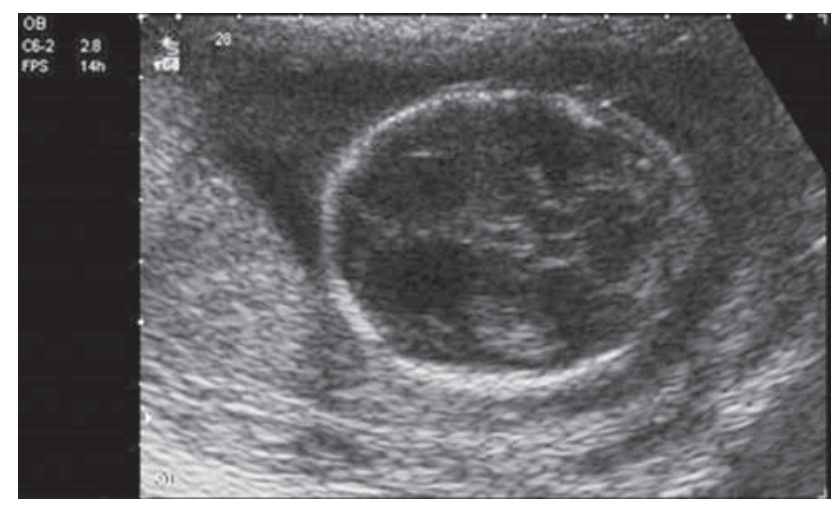

FIGURA 1. Ventriculomegalie „borderline“ bilaterală la 19 săptămâni gestaționale

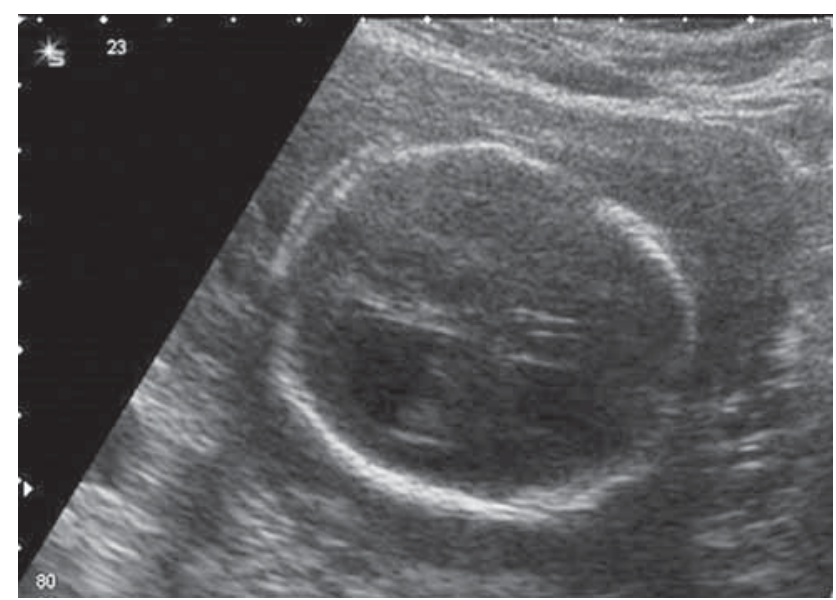

FIGURA 2. Acelaşi făt, la 21 de săptămâni gestaționale, cu progresia ventriculomegaliei

\section{Asimetrie sau ventriculomegalie?}

Asimetria ventriculilor laterali a fost raportată în cazul feților şi nou-născuţilor fără patologie cerebrală $(31,32)$. Un anumit grad de asimetrie a ventriculilor laterali a fost descris la creierul fetal, detectabil in utero, însă cu evoluție ulterioară normală (33-35). În concluzie, asimetria ventriculilor laterali nu este echivalentă cu ventriculomegalia.

\section{Ventriculomegalie uni- sau bilaterală?}

Într-un studiu efectuat pe 101 feți diagnosticați în viaţa intrauterină cu ventriculomegalie uşoară, 


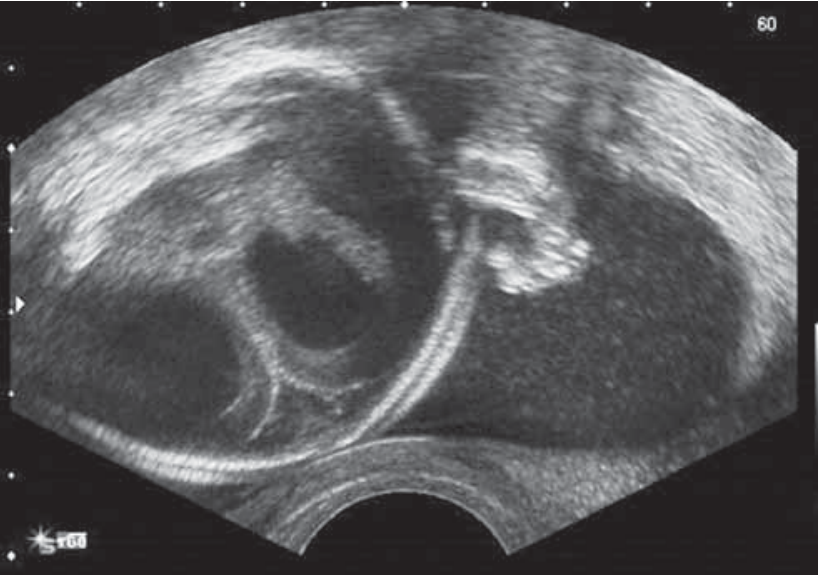

FIGURA 3. Acelaşi făt, la 21 de săptămâni gestaționale, cu ventriculomegalie progresivă, abord transvaginal

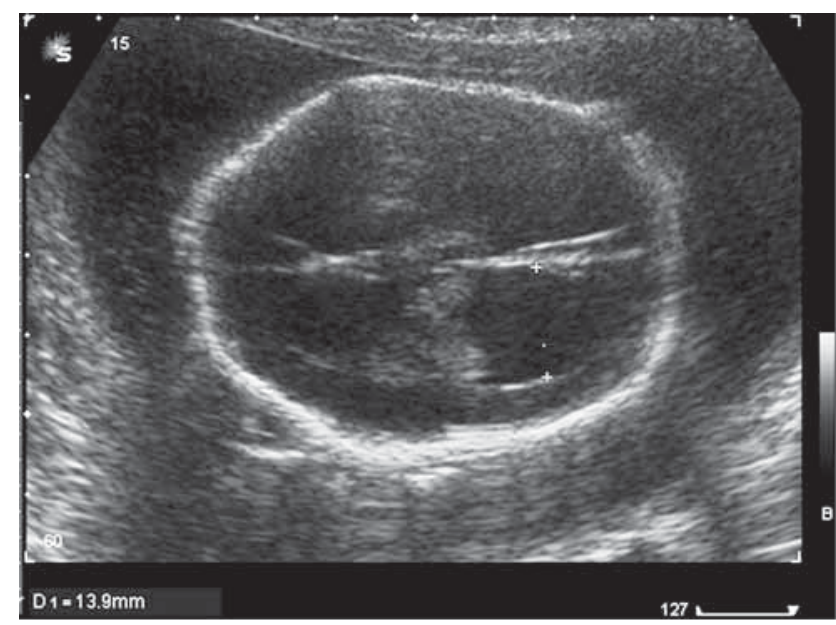

FIGURA 4. Ventriculomegalie moderată, la 21 de săptămâni gestaționale

evaluând ambele emisfere cerebrale, Falip et al au identificat o incidență a ventriculomegaliei unilaterale de $60 \%$ (36), în timp ce Boito et al au demonstrat o frecvență relativ identică a ventriculomegaliei uni- sau bilaterale în al doilea trimestru de sarcină (26).

\section{ETIOLOGIE}

Ventriculomegalia unilaterală reprezintă dilatarea progresivă a unui singur ventricul lateral din cauza unei perturbări circulatorii a lichidului cefalo-rahidian. Cea mai frecventă cauză a acestei perturbări este reprezentată de obstrucția foramen Monro. Atrezia congenitală este o altă cauză. Obstrucția morfologică a acestui orificiu poate fi cauzată de hemoragie, gliom sau anomalii vasculare, pe când obstrucția fizică a acestui orificiu poate fi datorată infecțiilor sau traumatismelor. A fost descrisă, de asemenea, şi obstrucția funcțională după ventriculostomie din cauza acțiunii valvei într-un singur sens (37).
Ventriculomegalia „borderline“ poate fi asociată cu anomalii cromozomiale, infecții congenitale, accidente vasculare cerebrale sau hemoragie, precum şi cu alte anomalii extracerebrale $(10,11,14)$. Astfel, infecțiile congenitale, precum cele cauzate de toxoplasmă, citomegalovirus şi rubeolă pot fi asociate cu ventriculomegalia uşoară. Mai multe studii au demonstrat că ventriculomegalia „borderline“ este prezentă în aproximativ $18 \%$ dintre cazurile diagnosticate $\mathrm{cu}$ infecție cu cytomegalovirus (3841). Trombocitopenia feto-neonatală autoimună, deşi prezintă o incidență scăzută, poate duce la hemoragie intracraniană, apoi porencefalie şi ventriculomegalie diagnosticată pre- sau postnatal (4248). Macrocefalia poate fi, de asemenea, asociată cu ventriculomegalia ,borderline“ (49).

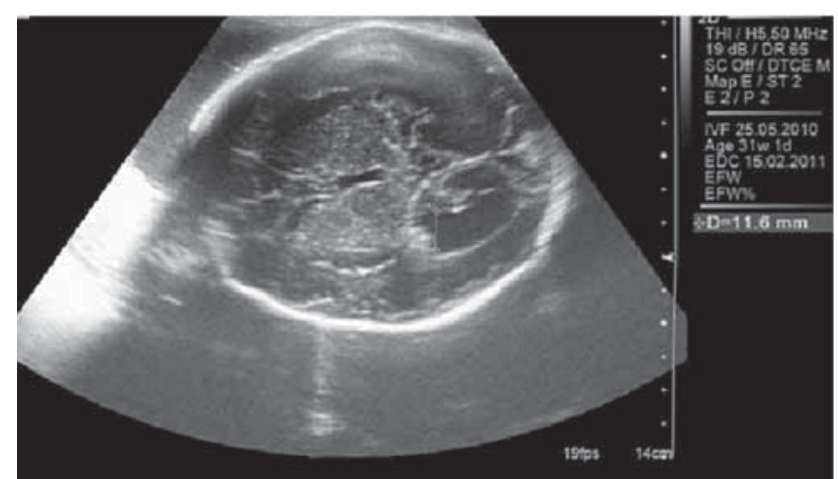

FIGURA 5. Macrocefalie la 31 de săptămâni gestaționale, cu circumferința craniană mai mare cu 2 deviații standard. Măsurarea ventriculului lateral în atriu, la glomus, de $11,6 \mathrm{~mm}$

\section{EVOLUȚIE NEONATALĂ ŞI PROGNOSTIC}

Incidenţa retardului în dezvoltarea neurologică ulterioară a feților şi nou-născuților diagnosticați cu ventriculomegalie uşoară variază foarte mult, însă Melchiorre et al raportează în review-ul său o incidenţă de aproximativ $11 \%$ şi concluzionează că nu există date clare care să sugereze o rată crescută a tulburărilor neuropsihiatrice, precum autism, ADHD, probleme de memorare sau schizofrenie la copiii diagnosticați prenatal $\mathrm{cu}$ ventriculomegalie uşoară izolată (10). De asemenea, Beeghly et al sugerează că gradul ventriculomegaliei nu este asociat cu dezvoltarea postnatală ulterioară, însă funcția motorie este mai întârziată decât cea cognitivă sau adaptativă la vârsta de 2 ani (50). Pe de altă parte, într-un alt studiu a fost identificată o asociere pozitivă între retardul neurologic şi gradul dilatării ventriculilor laterali (51). Cu toate acestea, într-un studiu longitudinal, a fost demonstrat că dezvoltarea neurologică între 18 luni şi 10 ani este normală în cazul feților şi nou-născuților diagnosticați cu ventriculomegalie ,borderline“ $(8,52)$. 
Factori care influențează prognosticul. Au fost descrişi anumiţi factori cu rol asupra prognosticului copiilor diagnosticați cu ventriculomegalie uşoară, şi anume: sexul $(10,36)$, vârsta gestaţională $(53,54)$, dimensiunea ventriculilor $(3,5,7,8,30,39)$, afectarea uni- sau bilaterală $(8,13,30,37)$, ventriculomegalie bilaterală simetrică sau asimetrică $(8,30,36)$, progresia ventriculomegaliei - probabil cel mai important factor al prognosticului 10), regresia ventriculomegaliei $(54,55)$.

\section{Ventriculomegalie „borderline“ - follow-up}

Conform recomandărilor franceze ale „High Authority of Health regarding the management of fetal cerebral ventriculomegaly“, intervalul minim înainte de a efectua o ecografie fetală de control după o evaluare inițială detaliată ar trebui să fie de două săptămâni (56), însă din experiența noastră, considerăm că evaluarea ecografică de control ar trebui să fie la o săptămână după diagnostic.

\section{Consiliere medicală în cazul cuplului cu făt diagnosticat cu ventriculomegalie „borderline“}

În ciuda lipsei unor dovezi clare, retardul ulterior în dezvoltarea neurologică a feților şi nou-născuților diagnosticați cu ventriculomegalie trebuie luat în considerare întotdeauna. Astfel, părinții trebuie informați despre faptul că există limitări ultrasonografice în diferențierea unei ventriculomegalii „borderline“ izolate şi ventriculomegalie asociată unor altor anomalii oculte, care nu pot fi identificate iniţial. Efectuarea unei rezonanțe magnetice nucleare RMN fetal este preferabilă dacă se suspicionează şi alte anomalii cerebrale. În funcție de alţi factori de prognostic nefavorabil asociați, decizia unui avort terapeutic trebuie luată în considerare.
Vârsta gestațională a diagnosticului joacă un rol decisiv în prognostic, investigații, evoluție, consiliere şi decizie. Diagnosticul intrauterin sau chiar suspiciunea de ventriculomegalie „borderline“ trebuie confirmată şi evaluată ulterior de către un pediatru, la aproximativ 6-7 săptămâni după naştere. În cazul în care se depistează sindroame genetice asociate ventriculomegaliei, sfatul genetic este necesar în cazul sarcinilor ulterioare.

\section{CONCLUZII}

Evaluarea ecografică a ventriculilor cerebrali se efectuează de rutină la morfologiile fetale din al doilea şi al treilea trimestru de sarcină. Ventriculomegalia „borderline“ presupune o dimensiune a ventriculilor între 10-12 mm. În cazurile în care este posibil şi există indicaţie, RMN-ul fetal trebuie, de asemenea, luat în considerare, precum şi analiza morfologică cromozomială. Testarea serologică pentru toxoplasmă şi citomegalovirus, precum şi titrarea anticorpilor ani-antigeni trombocitari trebuie, efectuate în cazul identificării unei hemoragii fetale cerebrale. Retardul neurologic în cazul feților şi copiilor diagnosticați $\mathrm{cu}$ ventriculomegalie „borderline“" este prezent în aproximativ 11\% dintre cazuri, însă cu variații largi. Factorii cei mai importanți care influențează prognosticul unei ventriculomegalii „borderline“ izolate sunt: asocierea altor anomalii evidențiate după momentul diagnosticului inițial, anomalii cromozomiale, infecții, trombocitopenie fetală autoimună, precum şi progresia dilatării ventriculare. Prin urmare, monitorizarea ecografică şi/sau RMN-ul sunt elemente cheie în evaluarea feților diagnosticați cu ventriculomegalie. 